\title{
한국에서 광역내성 Salmonella Typhi 첫 증례 The First Case of Extensively Drug-resistant Salmonella Typhi in South Korea
}

\author{
이난영 ${ }^{1,2} \cdot$ 함지연 ${ }^{1,2} \cdot$ 송경은,2 $\cdot$ 김석호 ${ }^{3}$ \\ Nan Young Lee, M.D. ${ }^{1,2}$, Ji Yeon Ham, M.D. ${ }^{1,2}$, Kyung Eun Song, M.D. ${ }^{1,2}$, Shukho Kim, Ph.D. ${ }^{3}$ \\ 칠곡경북대학교병원 진단검사의학과 ${ }^{1}$, 경북대학교 의과대학 임상병리학교실 ${ }^{2}$, 경북대학교 의과대학 미생물학교실 ${ }^{3}$ \\ Department of Laboratory Medicine ${ }^{1}$, Kyungpook National University Chilgok Hospital, Daegu; Department of Clinical Pathology², School of \\ Medicine, Kyungpook National University, Daegu; Department of Microbiology ${ }^{3}$, School of Medicine, Kyungpook National University, Daegu, \\ Korea
}

\section{Dear Editor,}

Typhoid fever, caused by Salmonella enterica subsp. enterica serovar Typhi ( $S$. Typhi), is one of the serious bloodstream infections that belongs to the class 2 of the legal infectious diseases in Korea. It has variable incubation period ranging from one to six weeks depending on the infectious dose [1,2] and requires urgent treatment with antimicrobial agents. However, recently, the prevalence of $S$. Typhi strains resistant to antimicrobial agents has been gradually increasing [3, 4]. This fact poses the failure of empirical treatment or a threat to the control of infectious typhoid fever [3]. In Korea, about 100-200 cases of typhoid are reported annually. To our knowledge, we report the first case of extensively drug-resistant (XDR) S. Typhi in Korea. Patient demographic and clinical information was collected from Sangju Red Cross Hospital (Sangju, Korea) by formally applying for access to the medical records of the outsiders and the informed consent from the patient. This study was exempted by the Institution Review Board of Kyungpook Na-

\section{Corresponding author: Kyung Eun Song, M.D., Ph.D.}

\section{(10) https://orcid.org/0000-0003-1628-4741}

Department of Laboratory Medicine, Kyungpook National University Chilgok Hospital; Department of Clinical Pathology, School of Medicine, Kyungpook National University, 807 Hoguk-ro, Buk-gu, Daegu 41404, Korea

Tel: +82-53-200-2831, Fax: +82-53-200-3309, E-mail: kesong@knu.ac.kr

Received: January 31, 2020

Revision received: March 31, 2020

Accepted: April 8, 2020

This article is available from https://www.labmedonline.org (C) 2020, Laboratory Medicine Online

(a) This is an Open Access article distributed under the terms of the Creative Commons Attribution Non-Commercial License (https://creativecommons.org/licenses/by-nc/4.0/) which permits unrestricted non-commercial use, distribution, and reproduction in any medium, provided the original work is properly cited. tional University Chilgok Hospital (Reference number: KNUCH 2019-04-015).

A 28-year-old male patient having fever and cough for a day visited the emergency department on the next day. He was found negative for the influenza antigen test and was discharged with a three-day prescription of cefdinir. After three days, he visited the emergency department again with the same symptoms and worsening diarrhea. Therefore, the treatment was switched to amoxicillin and a $\beta$-lactamase inhibitor. However, due to uncontrolled fever and significantly worsened diarrhea, he was hospitalized. Chest X-ray and abdomen CT scan were unremarkable except an evidence of probable mesenteric lymphadenitis. Therefore, he was treated with ceftriaxone for five days; however, his symptoms did not improve. Although his history was unremarkable, the symptoms began in 26 days after his arrival in Korea from a visit to Pakistan. AST, ALT, and ALP were moderately increased, but all the viral hepatitis markers were negative. Stool culture for Salmonella spp., Shigella spp., Vibrio spp., and Clostridium difficile showed negative until discharge. The toxin $\mathrm{A}$ and $\mathrm{B}$ assay for $C$. difficile was negative. However, blood culture revealed positive and Salmonella ser. Typhi was identified by using the Vitek2 Gram-negative identification system (bioMérieux, Durham, NC, USA). Serotyping for Salmonella spp. by serum agglutination test using Salmonella antisera (Joongkyeom, Goyang, Republic of Korea) revealed group D. However, anti-microbial susceptibility tests showed MICs for ampicillin, trimethoprim/sulfamethoxazole, and cefotaxime at $\geq 32 \mu \mathrm{g} / \mathrm{mL}, \geq 320 \mu \mathrm{g} / \mathrm{mL}$, and $\geq 64 \mu \mathrm{g} / \mathrm{mL}$, respectively, using the Vitek2 AST-N224 system (bioMérieux) and for ciprofloxacin at $\geq 2 \mu \mathrm{g} / \mathrm{mL}$ by the manual microdilution, according to the 
CLSI guidelines [5]. Therefore, it was strongly suspected to be an XDR $S$. Typhi strain, which was resistant to three first-line antibacterial agents (chloramphenicol, ampicillin, and trimethoprim/ sulfamethoxazole) as well as fluoroquinolones and third-generation cephalosporins. The isolate confirmed as Salmonella enterica subsp. enterica Ty 2 through the $16 \mathrm{~S}$ rRNA sequencing (Identities= 1,384/1,385, 99.93\%). The bla $a_{\mathrm{CTx}-\mathrm{M}-15}$ extended-spectrum $\beta$-lactamase (ESBL) gene and a single mutation in gyrA (S83F) were detected. His symptoms improved upon changing the treatment with intravenous administration of carbapenem for 14 days according to the United States CDC report [6] once the XDR $S$. Typhi was identified. He was discharged on day 23 after admission.

The emergence of $S$. Typhi strains resistant to antimicrobial agents leads to treatment failure and treatment change in antimicrobial policy. Ciprofloxacin was the drug of choice for typhoid fever in 1997 as S. Typhi strains were resistant to chloramphenicol, ampicillin, and trimethoprim, i.e., multidrug-resistant (MDR) since 1989 [7]. After that, the choice for treating the typhoid fever is primarily fluoroquinolones, followed by cephalosporins [4]. However, concurrent resistance to the third-generation cephalosporins by ESBL and ciprofloxacin for Salmonella spp. has been reported [3, 4]. Even more, XDR S. Typhi (accession no. LT882486.1) has been reported as an outbreak in Pakistan in 2016-2017 and as travel-associated typhoid fever [6, 8-10]. Travel-associated typhoid fever is defined as a case of typhoid fever with an onset of illness within one month after returning to the country from abroad [2, 6, 9]. Within a month of returning to Korea from a visit to Pakistan, his typhoid symptoms began and $S$. Typhi was confirmed in the blood culture.

The bla $_{\mathrm{CT \textrm {X } - \mathrm { M } - 1 5}}$ ESBL gene and a single mutation in gyrA (S83F) supported the relevance between the isolate and Pakistan [4, 8-10]. In the case of suspected travel-associated typhoid fever, caution should be taken to choose empirical antimicrobial therapy. The patients with travel history to Pakistan are recommended to be treated with azithromycin for uncomplicated typhoid fever and with carbapenems for complicated typhoid fever, including encephalopathy, intestinal perforation, intestinal hemorrhage, peritonitis, hepatitis, or bacteremia [6].

In conclusion, we should pay attention to the emergence of XDR strains of $S$. Typhi because in addition to restricting the choice of antibiotics, it may be difficult to treat the typhoid fever with the existing antibiotics when these strains become the norm.

\section{Conflicts of Interest}

None declared.

\section{Acknowledgements}

The authors thank medical doctors, Sang Su Lee, Woo Kyung Sung, and Kyung Min Lee and medical laboratory technologist Eun Jeong Lee at Sangju Red Cross Hospital for cooperating with this study.

The pathogenic strain for this study was provided by the Kyungpook National University Hospital Culture Collection for Pathogens, a member of the National Biobank of Korea, which is supported by the Ministry of Health and Welfare.

\section{REFERENCES}

1. Buchan BW, Faron ML, Humphries RM, Dekker J, Ledeboer NA. Escherichia, Shigella, and Salmonella. In: Carroll KC, ed. Manual of clinical microbiology. 12th ed. Washington DC: ASM Press, 2019:688-723.

2. Freedman J, Lighton L, Jones J. Defining travel-associated cases of enteric fever. J Infect Public Health 2014;7:377-85.

3. Wong MH, Yan M, Chan EW, Biao K, Chen S. Emergence of clinical Salmonella enterica serovar Typhimurium isolates with concurrent resistance to ciprofloxacin, ceftriaxone, and azithromycin. Antimicrob Agents Chemother 2014;58:3752-6.

4. Britto CD, Wong VK, Dougan G, Pollard AJ. A systematic review of antimicrobial resistance in Salmonella enterica serovar Typhi, the etiological agent of typhoid. PLoS Negl Trop Dis 2018;12:e0006779.

5. Clinical and Laboratory Standards Institute. Performance standards for antimicrobial susceptibility testing. 29th ed. CLSI supplement M100. Wayne, PA: Clinical and Laboratory Standards Institute, 2019.

6. Chatham-Stephens K, Medalla F, Hughes M, Appiah GD, Aubert RD, Caidi H, et al. Emergence of extensively drug-resistant Salmonella Typhi infections among travelers to or from Pakistan - United States, 20162018. MMWR Morb Mortal Wkly Rep 2019;68:11-3.

7. Rowe B, Ward LR, Threlfall EJ. Multidrug-resistant Salmonella typhi: a worldwide epidemic. Clin Infect Dis 1997;24:S106-9.

8. Klemm EJ, Shakoor S, Page AJ, Qamar FN, Judge K, Saeed DK, et al. Emergence of an extensively drug-resistant Salmonella enterica serovar Typhi clone harboring a promiscuous plasmid encoding resistance to fluoroquinolones and third-generation cephalosporins. mBio 2018;9:e00105-18. 
9. Wong W, Rawahi HA, Patel S, Yau Y, Eshaghi A, Zittermann S, et al. The first Canadian pediatric case of extensively drug-resistant Salmonella Typhi originating from an outbreak in Pakistan and its implication for empiric antimicrobial choices. IDCases 2019;15:e00492.
10. Yousafzai MT, Qamar FN, Shakoor S, Saleem K, Lohana H, Karim S, et al. Ceftriaxone-resistant Salmonella Typhi Outbreak in Hyderabad City of Sindh, Pakistan: High Time for the Introduction of Typhoid Conjugate Vaccine. Clin Infect Dis 2019;68:S16-21. 